\title{
Undergraduate Students' Engagement with Systems Thinking: Results of a Survey Study
}

\author{
Fanny Camelia, Timothy L.J. Ferris, Senior Member, IEEE
}

\begin{abstract}
This paper describes the results obtained for the affective engagement of students with systems thinking. In prior work the authors have developed and validated a questionnaire instrument for measuring affective engagement of undergraduate engineering students with systems thinking. This paper presents results obtained when the questionnaire was used with undergraduate students. Two surveys with different versions of the questionnaire, one using positive grammar questions only and the other using a mix of positive and negative constructs, were used to measure the students' engagement with systems thinking and its relationship with gender, age and work experience. Each questionnaire version was applied to a different sample, the first, 186 participants, completed the positive grammar version, and, the second group of 163 completed the mixed version. The results show that participants in both studies valued systems thinking in each of the three dimensions of the systems thinking construct. Statistical tests confirmed no significant gender differences in either study. Student engagement with the practical dimension of systems thinking was shown to vary, with statistical significance, with groups of age, years of work experience and country of the university.
\end{abstract}

Index Terms-systems thinking, systems engineering, systems engineering education, systems engineering and theory, affective domain

\section{INTRODUCTION}

S ystems thinking (ST) refers to conceptual understanding or mental constructs of the system of interest [1, 2]. It involves the perception and conceptualization processes by applying ST rules including: questioning the system boundary; system structure and interrelationship; adopting multiple perspectives; considering change over time (dynamic characteristics); and applying holistic and big picture view [28]. These actions can be enhanced by use of various ST tools and methods $[9,10]$.

In systems engineering (SE), ST serves as a bridge between theory and practice, and between the abstract (intellectual domain) and concrete (practical domain). It is essential for systems engineers to facilitate a thorough understanding of the

Manuscript received XXX/XXX/XXXX. This work was supported by Indonesia Directorate General of Higher Education through DGHE PhD scholarship.

F. Camelia is with the Industrial Engineering Department, Ekasakti University, Padang, Indonesia, and with the School of Engineering, University of South Australia, Mawson Lakes, SA 5095 (e-mail: fanny.camelia@mymail.unisa.edu.au).

T.L.J. Ferris is with the Centre for Systems Engineering, Cranfield University, Defence Academy of the United Kingdom Shrivenham, SN6 8LA UK, and has an adjunct position with School of Engineering, University of South Australia, Mawson Lakes, SA 5095 (e-mail: timothy.ferris@cranfield.ac.uk). system, of how it will work and how it interacts with stakeholders and the environment, often in support of problem solving and decision making. Frank's study of ST in SE asserted that a successful systems engineer must have a developed capacity for ST [11]. However, surprisingly, there is only a limited literature showing how ST is applied in SE. Although there are some studies, by Frank [12-18], Davidz [7] and Lamb [19], all of whom investigated professional systems engineers, there is a lack of research about ST in SE education and among SE undergraduate students in particular [1,20].

In other disciplines, some studies have been conducted to measure students' ST in classrooms at various grades [21-26]. However, most of the quantitative studies are based on the cognitive perspective only, that is, what students learn. There is a lack of research about students' affective engagement with ST. This distinction builds on Bloom's taxonomy of educational outcomes which classifies learning into cognitive, affective and psychomotor domains [27]. The cognitive domain addresses the development of intellectual abilities and skills related to knowledge of content and ability to use that knowledge. Affective domain development deals with students' emotions, feelings and valuation of the cognitive aspects. The psychomotor domain deals with performing sequences of physical activity to specified quality and quantity [28].

In the absence of quantitative research about affective engagement with ST in SE education, correlations of ST with other student attributes have not been explored. This paper explains the affective domain in education, and the linkage of the affective domain perspective in ST and SE. This paper reports students' affective engagement with ST and its correlation with gender, age, work experience and country of origin of the university.

\section{BACKGROUND AND LITERATURE REVIEW}

\section{A. Importance of the Affective Domain in Education}

The separation of mind and matter, which is traditional in Western thought, has had a significant influence on metapsychological theories of thinking and emotion [29]. Emotions were either ignored or treated as "an unwelcome source of noise" or bias in relation to "normal" cognitive function [29, p. 35]. Similarly, in education, especially in higher education, the cognitive domain receives most attention [29-31], leading to the neglect of the affective domain [29, 31-34]. Research about the affective domain outcomes of education is rare [34, 35]. This neglect arises from the unclear definition of affective constructs, the underdeveloped assessment practices related to the affective domain, and the lack of frameworks or models for supporting the utilization of the affective dimension in 
DOI: 10.1109/TSMC.2016.2563386. Camelia F, Ferris TLJ (2016); Undergraduate Students' Engagement With Systems

Thinking: Results of a Survey Study. IEEE Transactions on Systems Man and Cybernetics: Systems IEEE Early Access Article

teaching cognitive learning [33, 34]. Another reason for this neglect is the prolonged appreciation of the cognitive aspect of education research and archetypal image of 'science' which seeks to differentiate reason from feeling [34]. In addition, the affective domain is not of equal importance in all disciplines.

However, numerous studies in other fields have shown the affective domain generates physiological changes which are also indicative of learning [29, 34, 36]. This knowledge can be used to gain further insight into the learning process [29]. Recent studies in neuroscience have found an overlap of the brain regions involved in processing emotions and cognitive processes [29, 34, 37] demonstrating a connection between cognition and emotion [29, 37]. Emotions, as fundamental brain function, are a learning condition and it is reasonable to believe that students' affective quality can be developed during education.

In turn this connection between affective and cognitive processing is important for the improvement of teaching and learning [34] because none of the components in education, such as 'concept' and 'emotion', is separate [29]. Concept and emotion are interacting determinants of each other [32]. The affective dimension of learning - the key factor in how students feel, act, and think [29], playing a key role in facilitating effective cognitive processes necessary for internalization of cognitive content and enhancing students' integrative capability $[29,32,33]$. A positive outcome in the affective domain is considered to be an important antecedent to the cognitive success [38]. Thus, in the contemporary view, the affective dimension is regarded not just as a simple catalyst, but as an essential learning condition [34].

\section{B. Affective Dimension in Systems Engineering Education}

In engineering education generally and SE in particular, the affective aspect of learning is relatively less appreciated compared to the cognitive aspect of learning [33, 36, 39, 40]. Existing engineering education practice emphasizes acquisition of knowledge (cognitive dimension) with less emphasis on valuing the acquired knowledge (affective dimension) [36]. Consequently engineering is often perceived as object rather than people-oriented [33, 36]. Research in engineering education also pays more attention to improving student learning from a content-oriented, cognitive, perspective [39]. The role of affective development during knowledge and skill transfer has not been well comprehended by engineering educators leading to limited awareness and application of it in the teaching and learning process [36, 39].

Engineering educators often associate the affective domain with the 'soft skills' necessary for practice [28, 41-44]. The view which associates the affective with soft skills results in the two domains being interpreted as being about different subject areas of knowledge rather than as different dimensions of the learner in relation to holistic engagement in education [44].

Our interpretation of the affective dimension builds on the view of education as an holistic activity which can be viewed from the facets of Bloom's three domains as facets of achievement of the student and, later, graduate, with respect to a single, holistic, set of learning objectives [2, 44]. As such there is an engagement of learning of content, a cognitive outcome, and developing the student to be 'characterized' by the methods and approaches that are taught in the cognitive space. That is, the student becomes characterized by beliefs in the value and appropriateness of the application of the knowledge and capabilities developed through the cognitive dimension of their education, thus taking the knowledge, skills and abilities as their default manner of approaching systems engineering tasks.

The affective engagement in SE education is concerned with attitudes and behaviors rather than 'affective competencies' development. This is important given the earlier views of the affective domain in engineering education, where it appears that some authors interpret affective learning as learning about 'affective topics'. The latter is cognitive engagement with a topic characterized as 'affective'. For example, professional ethics, one of the affective topics, is often associated with the affective domain, since there is a clear association with the value system hold by an individual $[44,45]$. The emphasis of Bloom's, and our, view is that affective learning results in transforming the student to be characterized by valuing the cognitive subject matter learned The kind of development sought is that the student come to believe in the value of the SE approach to engineering to an extent that they can overcome other driving forces that often result in non-systemic approaches to engineering work.

\section{Affective Engagement With Systems Thinking in Systems Engineering Education}

As previously introduced (section I), ST helps systems engineers to work with engineered systems to support problem solving and decision making. Studies in neuroscience and neuropsychology suggested that emotions influence problem solving and decision making [46]. Emotion enables fast decision making because the process is almost 'instantaneous', 'automatic' and 'non-conscious' [46]. Therefore, the implicit use of unconscious mental processing includes a vast amount of biases-knowledge and learning that have already been internalized [46]. Systems engineers must be aware of the knowledge, assumptions and biases that impact their practice, but most of this is normally only non-consciously known. Often important, apparently non-emotional, decisions are influenced by emotional driving factors [46], with emotions and values always having some impact, and often enabling more efficient decision making. Often logical processes are developed as rational justifications for existing emotional decisions.

Individuals with emotional impairments, such as arising from damage to the limbic area of the brain, may retain most cognitive abilities, such as perception and intelligence [46], but struggle to make judgments and make poor decisions. This implies that effective decision making and judgment involve integration of cognition and emotion, which together form the affective domain in education [46-49]. Systems engineers, therefore, can improve their SE practice through integration of the ST approach, and belief in ST as a sound guiding approach for dealing with complex engineering matters.

Avoiding jumping to conclusions about the appropriate approach to a project under both normal conditions, where one may be tempted to assume one knows the right approach, or under challenging conditions, where performing ST may 
DOI: 10.1109/TSMC.2016.2563386. Camelia F, Ferris TLJ (2016); Undergraduate Students' Engagement With Systems

Thinking: Results of a Survey Study. IEEE Transactions on Systems Man and Cybernetics: Systems IEEE Early Access Article

appear to delay project completion, it is necessary for the systems engineer to highly value and be characterized by using ST in systems engineering. To achieve this characterization in the graduate, cognitive development is necessary, to provide the necessary technical skills. It is also necessary to develop the student's engagement with these skills to characterize the graduate by the use of these technical skills. In affective characterization by ST it is expected that the student will naturally, routinely and intuitively use ST in their systems engineering work, even when confronting challenges such as perceived urgency of the project.

SE education must not only emphasize teaching the cognitive domain elements of ST but systems engineering educators also need to emphasize the student's engagement with cognitive content in a manner that influences the student's beliefs and interests related to ST and which leads to characterization by the perspectives of ST, the affective domain $[2,44,50]$. The result of our investigation of measurement of students' cognitive development in ST [51] and the validation studies of the questionnaire to measure students' affective engagement with ST [2, 52] are published elsewhere. This paper discusses the result of our measurement of students' affective engagement with ST and reports the correlations of gender, age, work experience and country of the origin university with students' engagement with ST. The contribution of this paper is the findings about the students which the validated questionnaire has enabled.

\section{RESEARCH QUESTIONS AND METHODS}

Two descriptive surveys with two versions of the questionnaire, one using only questions constructed using positive grammar and the other using a mix of positive and negative constructs, each applied to a different sample, were used to measure undergraduate engineering students' engagement with systems thinking and its relationship with gender, age, work experience and country of the university.

\section{A. Research Questions}

We report results of five research questions in this paper:

1. How well do students engage with the ST factors?

2. Is there a gender difference in how students engage with the ST factors?

3. Is there age dependency in students' engagement with the ST factors?

4. Is there a work experience quantity difference in students' engagement with the ST factors?

5. Is there a difference in students' engagement with the ST factors related to their university of study?

\section{B. Participants}

The population of interest in this study is undergraduate students of SE, taught both in domain centric and systems centric programs, using Fabrycky's distinction of program focus [53]. This study employed a non-probability sampling method where participants are not selected by chance, but by some other means [54]. Convenience sampling was used, since participants were selected because they were available to be studied and represent some characteristics of the population. We approached 30 universities in Australia, Indonesia and
USA in which undergraduate students are offered either a domain centric or systems centric program including studies in SE and ST. We received participation from students in four universities, located in three countries, and one of which also offered a relevant program in Singapore. In each university whole classes were invited to participate. Each student was free to choose to participate, or not. There is potential bias in the results of our work resulting from this but we have no basis for identifying any particular bias. 186 undergraduate engineering students enrolled in an SE course in one of four universities in Australia, Singapore, Indonesia and the US completed the first version of the questionnaire, the positive items questionnaire. Whereas, 163 undergraduate engineering students enrolled in an SE course in one of three universities in Australia, Singapore and the US completed the second version of the questionnaire, with a mix of positive and negative items.

The general rule in quantitative analysis is to use the largest possible of sample. The larger the sample, the more likely the research participants' scores on the measure variables will be representative of population scores for the population of which the sample is actually representative, as distinct from the population that the researcher thought they were investigating, through the reduction in the impact of any outlier responses that could have an appreciable effect in a small sample. In addition to this general rule, researchers have developed rules of thumb for determining the minimum number of participants needed for different research methods. For a research survey, it is suggested that a minimum of 100 participants is appropriate [55].

The recruitment of participants and collection of data was performed according to the approved ethics protocol, 0000031508, University of South Australia.

\section{Materials}

The self-report measure, in various technologies, is the most common data collection method used by researchers measuring the affective domain. This method asks subjects to report the extent of particular experiences, thoughts or feelings in their life [54]. An attitude scale is a form of self-report measure which is used to measure an individual's viewpoint or disposition toward a particular object. A commonly accepted attitude scale is the Likert scale asks multiple questions about attitude matters and assumes each item has equal attitudinal value.

Two surveys, using two versions of a 30 item self-report questionnaire adapted from Frank's CEST instrument [56]. The discussion of the questionnaire development and the entire 30 question survey were provided in [2, 52]. Each question offers a seven point Likert scale for response with possible response categories ranging from: 'very untrue', to 'very true'. As part of our work to validate the scale, two versions of the questionnaire were employed with distinct samples of subjects. In the first survey, all questionnaire items used positive expression and in the second some questions were reworded to use negative grammar. The theory behind this construction is to avoid the problem of respondents answering on one side of the middle-point of the scale throughout [57]. It is also 
DOI: 10.1109/TSMC.2016.2563386. Camelia F, Ferris TLJ (2016); Undergraduate Students' Engagement With Systems Thinking: Results of a Survey Study. IEEE Transactions on Systems Man and Cybernetics: Systems IEEE Early Access Article intended to encourage participants to read each question thoughtfully [52].

TABLE I

M1 AND M2 DESCRIPTION AND INTERPRETATION BASED ON PERSPECTIVE OF THE NATURE OF SYSTEMS THINKING

\begin{tabular}{|c|c|c|c|c|}
\hline \multirow[t]{2}{*}{ Factor } & \multicolumn{2}{|l|}{ Model 1 (M1) } & \multicolumn{2}{|l|}{ Model 2 (M2) } \\
\hline & Factors in the learning of systems thinking & $\begin{array}{l}\text { Perspective on the } \\
\text { nature of systems } \\
\text { thinking }\end{array}$ & Factors in the learning of systems thinking & $\begin{array}{l}\text { Perspective on } \\
\text { the nature of } \\
\text { systems } \\
\text { thinking }\end{array}$ \\
\hline 1 & $\begin{array}{l}\text { Inclination towards taking holistic view and } \\
\text { interest in the activities of specialists in other } \\
\text { areas }\end{array}$ & Cross-disciplinarity & $\begin{array}{l}\text { Preference or inclination towards whole of systems } \\
\text { perspectives }\end{array}$ & Theoretical \\
\hline 3 & $\begin{array}{l}\text { Interest in and enjoyment of using system } \\
\text { modeling methods }\end{array}$ & Methods to do work & $\begin{array}{l}\text { Inclination towards participation in seeking a coherent, } \\
\text { whole, system solutions }\end{array}$ & Practical \\
\hline 4 & $\begin{array}{l}\text { Perception of interconnectedness of work } \\
\text { tasks done in a team }\end{array}$ & $\begin{array}{l}\text { Complexity and } \\
\text { holism }\end{array}$ & & \\
\hline 5 & Inclination to teamwork and organization & Bureacracy & & \\
\hline
\end{tabular}

TABLE II

QUESTIONS PRESENTED IN THE TWO SURVEYS BASED ON M2.

QUESTIONS IN THE FIRST SURVEY ARE IDENTIFIED BY S1, QUESTIONS IN THE SECOND SURVEY BY S2, AND OUESTIONS IN BOTH SURVEYS BY S1\&S2.

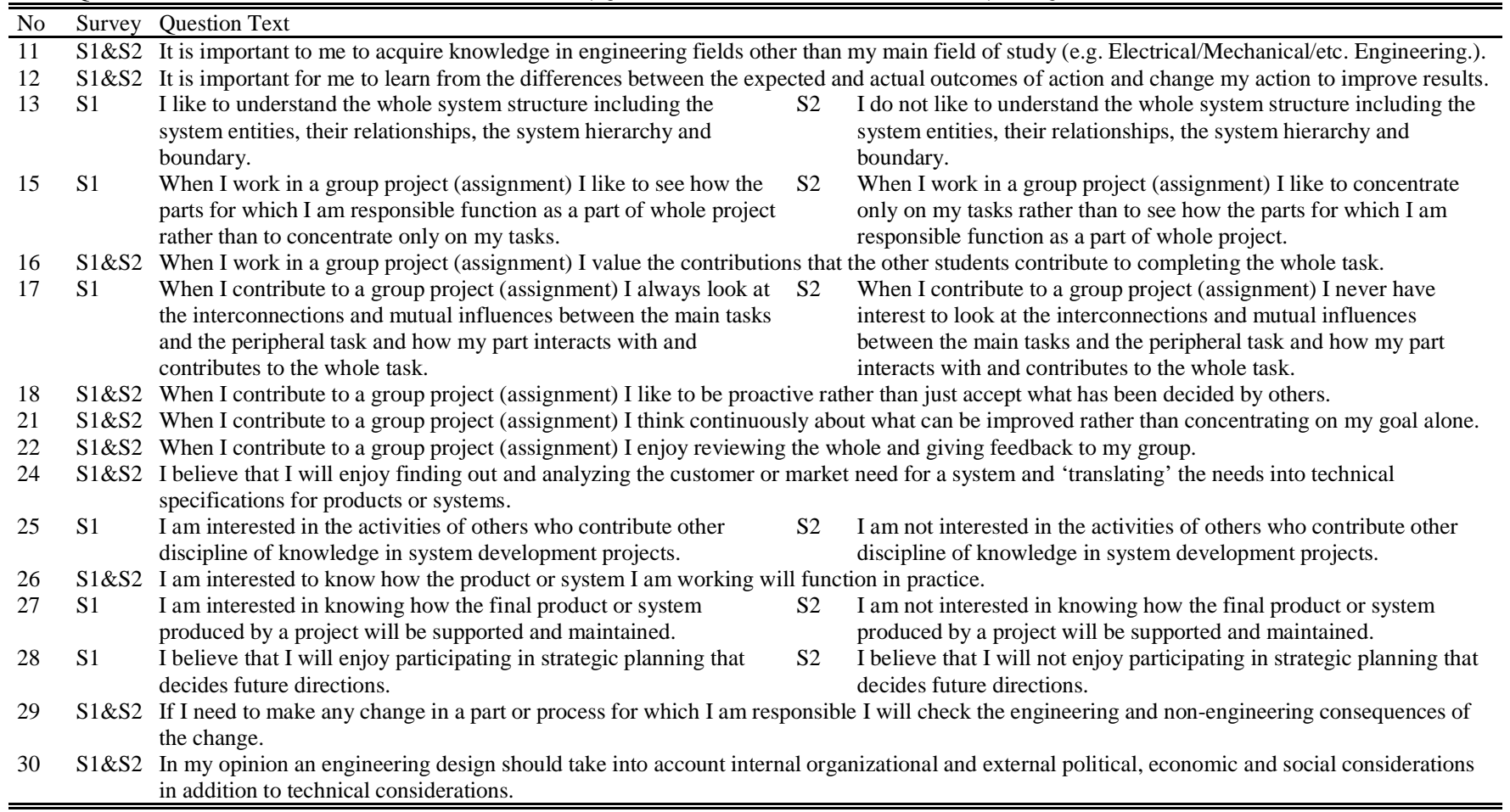

We conducted validation studies to choose the better version of the questionnaire, for recommendation for use in further study. These validation studies also aimed to explore the students' affective domain relation to ST by looking for the best construct underlying both questionnaires, thus the further analysis-which is reported in this paper-can be employed based on this best construct. The validation work was performed by applying Exploratory Factor Analysis (EFA) and Confirmatory Factor Analysis (CFA), which was reported in $[2,52]$ and summarized here.

In the first survey $[2,52]$ we found 22 questions grouped into five factors, which we called Model 1 (M1). Some questions had low loading factors $(<0.50)$, which indicate that they correlate weakly within their factor. Two questions had cross-loadings which differ by less than 0.2 , indicating poor discrimination. These findings indicate convergent and discriminant validity problems. In the second survey [52], we found 16 questions grouped into three factors, which we called Model 2 (M2). All questions contributing to each factor had high loading factors $(>0.55)$, which indicate that they correlate strongly within their factor. All questions had crossloadings which differ by at least 0.4 , indicating good discrimination. These findings indicate significantly better convergent and discriminant validity. The examination of convergent and discriminant validities confirmed that the second instrument with mixed positive and negative questions 
is more appropriate to measure students' effective engagement with the systems thinking and recommended for further use.

Table I shows the description of the factors produced by each model and interprets the factor as described for the perspective on the nature of ST and engagement with ST that the factor represents. The analysis of Table I shows that the two models are significantly different in their organization of ST. M1 reflects a phenomenological construct of kinds of activity to be done. Whereas M2 reflects a construct similar to that described by Kline's organization of an academic discipline and Checkland's summary of research elements into a framework of ideas, methodology and an area of concern $[58,59]$.

We concluded that it is more appropriate to infer M2 than M1 as the model because the structure of M2 addresses fundamental issues rather than phenomenological issues. This result was supported by the CFA result [52] using the data from each of the studies in the model developed by the other study. The comparative study showed that M2 provided a better fit to the data collected in both studies than was provided by M1. Therefore, whether the questionnaire has all positive items or mixed positive and negative items, the three factor model based on 16 items (M2) provides the better fit underlying both of versions of the questionnaire. This result shows that students' ST in the affective domain can be conceptualized according to three factors which reflect theoretical, methodological and practical aspects of ST. We excluded 14 items from the original 30 items of the questionnaire because our EFA and CFA work demonstrated that only the 16 items retained contributed in a statistically significant manner to the survey analysis and therefore interpretation of results obtained through the survey.

Table II shows the questions asked in the two surveys which contributed to M2. Some questions are common to both questionnaires and some of the questions are asked in a positive form in the first and a negative form in the second. These two forms are shown, where relevant.

\section{Data Analysis: Research Question 1}

To answer the first question, "How well do students engage with the ST factors?" we provide descriptive statistics. This method organizes, summarizes and displays the data, including calculating measures of central tendency and dispersion. Graphical display of the data also aids in assessing patterns of dispersion [60]. In addition, normality tests were conducted to determine if the distribution is normal. A normality test helps to determine whether parametric or non-parametric tests should be used in the next analysis. Parametric tests are based on the assumption that the data are sampled from a known population distribution, for example the normal distribution. Otherwise, non-parametric tests do not assume any particular distribution. Non-parametric tests are more conservative, but must be used when the pre-requisites for using parametric tests do not hold.

\section{E. Data Analysis: Research Questions 2, 3, 4 and 5}

To investigate the other research questions, "Is there a gender difference in how students engage with the ST factors?", "Is there age dependency in students' engagement with the ST factors?", "Is there a work experience quantity difference in students' engagement with the ST factors?", and "Is there a difference in students' engagement with the ST factors related to the country of their university of study?", we used the estimation and hypothesis testing methods of inferential statistics to assess the strength of the evidence, make comparisons, make predictions and draw conclusions about a population based on the sample [60]. Before analyzing the correlations with gender, age, work experience and university of study, we investigated whether the difference between the two surveys is significant or the data could be combined and analyzed as one, larger, sample.

\section{RESUlTS AND DisCUSSION}

\section{A. Participants \\ 1) Survey 1}

The first survey comprised 186 undergraduate engineering students enrolled in an SE course in one of four universities in Australia, Singapore, Indonesia and the US. Some were enrolled in each of systems-centric and domain-centric programs, $76 \%$ were male, $24 \%$ female, and the average age was 25.5 years. The distribution of participants was $26(14 \%)$ from Australia, 50 (27\%) from Singapore, 52 (28\%) from US and $58(31 \%)$ from Indonesia. $46 \%$ of participants were part time students, $52 \%$ full time students, and the rest (3\%) did not give their status. Further, $22 \%$ work part time, $45 \%$ full time and the others were not working. These participants responded to the version of the questionnaire with all positive construct questions.

\section{2) Survey 2}

The second survey comprised 163 undergraduate engineering students enrolled in an SE course in one of three universities in Australia, Singapore and the US. Some were enrolled in each of systems-centric and domain-centric programs, $88 \%$ were male, $12 \%$ female, and the average age was 27.0 years with a standard deviation of 6.7 years. The distribution of participants was $91(56 \%)$ from Australia, 59 (36\%) from Singapore and $13(8 \%)$ from USA. $46 \%$ were part time students, and the rest, 54\%, full time students. Further, $20 \%$ work part time, $40 \%$ full time and the others were not working. These participants responded to the version of the questionnaire with a mix of positive and negative construct questions.

\section{B. Question 1: Engagement with Systems Thinking}

\section{1) First Survey}

We used M2 to analyze the data provided by the 186 participants in the first survey. The answers to the 16 questions yielded a mean score of 5.5 out of 7 , with a standard deviation 0.724 . Scores of 5.1, 5.6, and 6.1 out of 7 represented the $25^{\text {th }}$, $50^{\text {th }}$, and $75^{\text {th }}$ percentiles, respectively. We conclude that participants showed their valuation of ST in their experience as developing engineers by showing a positive attitude when engaging with ST. Figure 1 provides the responses of participants to these 16 items. Table III summarizes the descriptive statistics of the 186 students' scores, from the first survey, in relation to the three factors in M2.

Both the skewness and kurtosis values obtained indicate non-normality of the distributions. The non-normality of the 
score distributions was confirmed by the Shapiro-Wilk test of normality. This test compares a Gaussian normal curve with the observed mean and standard deviation and the observed data. The Shapiro-Wilk normality test is more appropriate for smaller sample sizes $(n<2000)$ than the Kolmogorov-Smirnov test which is suitable for bigger samples $(n>2000)$ [61]. The result of the Shapiro-Wilk normality test is non-significant ( $p$. $0.00,0.00,0.01,<0.05)$, indicating non-normality of the three distributions of students' scores on the three factors. This indicates that non-parametric tests, tests which are not based upon the assumption that the data are sampled from a normal distribution, should be used for the next analysis.

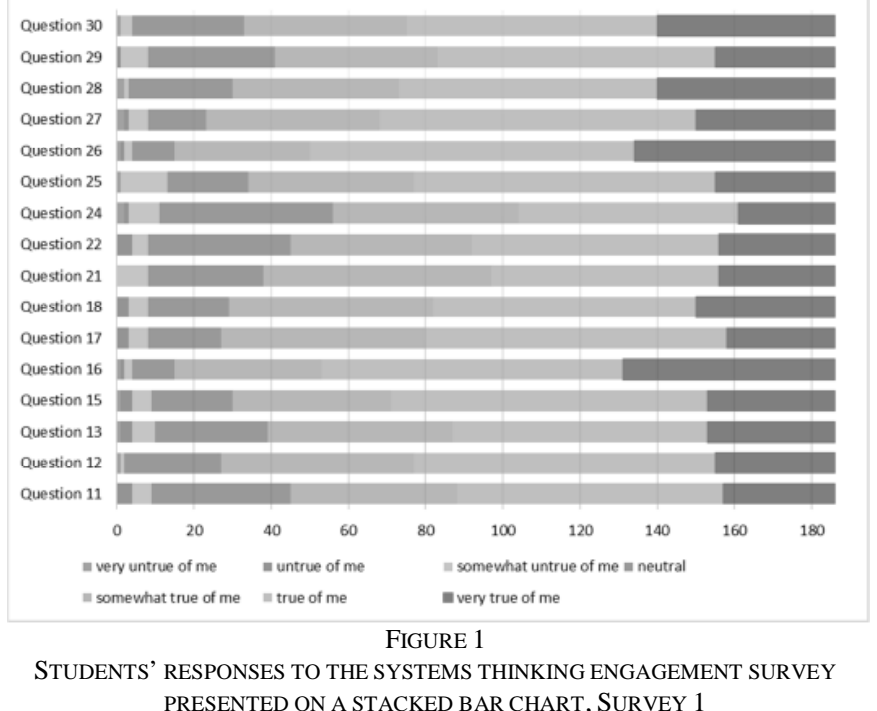

The correlations between factors were investigated using the Spearman correlation test, a non-parametric correlation test alternative for the parametric Pearson correlation which assumes a normal distribution. Table IV shows the correlation matrix for the three factors. There were positive and strong correlation $(>0.5)$ between students' preference towards ST theories (factor 1) and students' interest in ST methodologies (factor 2) $(r=0.778, n=186, p<0.01)$; positive and strong correlation between students' preference towards ST theories (factor 1) and students' inclination towards ST practice (factor $3),(r=0.746, n=186, p<0.01)$; and positive and strong correlation between students' interest in ST methodologies (factor 2) and students' inclination towards ST practice (factor $3), \quad(r=0.645, n=186, p<0.01)$. In general, this result suggests that students who have a positive attitude when engaging with one dimension of ST tend to rate themselves as valuing ST in other dimensions.

2) Second Survey

We used M2 to analyze the data provided by the 163 participants in the second survey. The answers to the 16 questions yielded a mean score of 5.2 out of 7 , with a standard deviation 0.716 . Scores of 4.6, 5.2 and 5.8 out of 7 represented the $25^{\text {th }}, 50^{\text {th }}$, and $75^{\text {th }}$ percentiles, respectively. We conclude that participants showed their valuation of ST in their experience as developing engineers by showing a positive attitude when engaging with ST. Figure 2 provides the responses of participants to these 16 items. In visually comparing figures 1 and 2 the respondents in Survey 2 show a broadly similar pattern of responses to the questions but with a tendency towards answering with a single step lower on the scale. Formal statistical discussion follows.

The data shows that the participants value ST, in its three factors, in their experience as developing engineers by showing a positive attitude towards ST theories, ST methodologies; and ST practice. The skewness values of the three factor distributions were $-0.851,-0.526,-0.508$, respectively, which indicates that the scores from each student clustered towards the right-hand side of the graph $[62,63]$. The kurtosis values, which provide information about the peakedness of the distribution, were $0.843,0.551$ and 0.385 , respectively. These kurtosis values indicate that this distribution is peaked with many scores clustered towards the center. This contrasts with the results from Survey 1 but is consistent with the visual observation of the difference between figures 1 and 2 mentioned above.

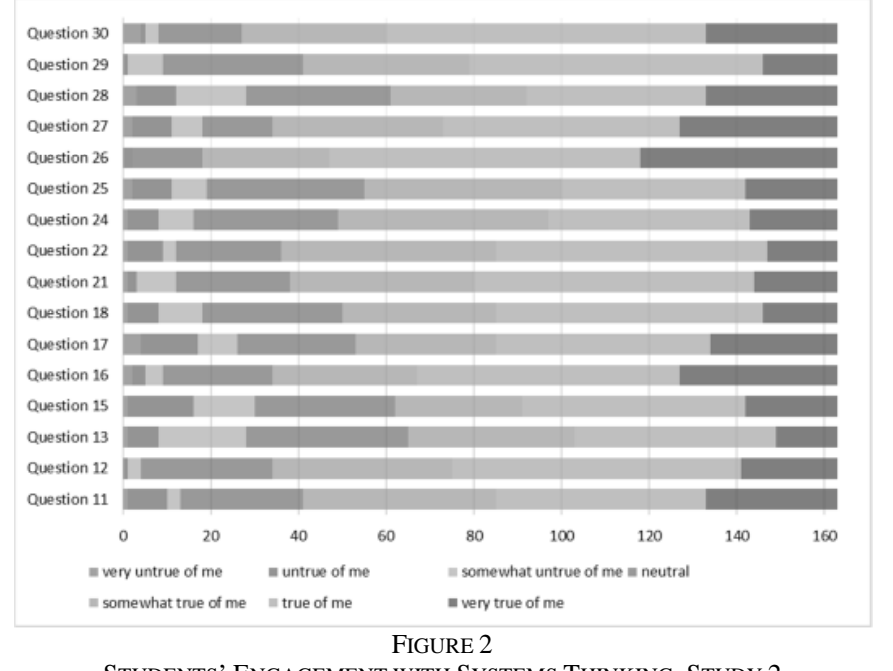

StUdENTS’ ENGAGEMENT WITH SySTEMS THINKING, STUdy 2

\section{Comparison of the Two Surveys Results}

Before analyzing the survey data correlated with gender, age, work experience and countries of university of study, we examined the difference of result of the two surveys to determine whether two data sets could be combined into a single, larger, sample or separately for each survey. We used Mann-Whitney U test, a non-parametric alternative to the t-test to compare the medians of each group (Survey 1 and Survey 2). The result of the Mann-Whitney $U$ tests are presented in Table V.

The Mann-Whitney $U$ test revealed that responses to 7 questions $(13,15,16,17,18,25$ and 28) are significantly different in the two survey at $p<0.05$. However, responses to the other questions, $(11,12,21,22,24,26,27,29$, and 30) are not significantly different at $p<0.05$. This indicates that combining both sets of data to get a larger sample is inappropriate, since over $40 \%$ of the questions have significantly different results because of changing the grammatical construct. We also note that 6 of the 7 questions with significant changes were questions for which the 
grammatical construct was changed, indicating a link of the change of construct and these results. Therefore analyzing separately for each survey. correlations of results with other factors must be conducted

TABLE III STUDENTS' ENGAGEMENT to SYSTEMS THINKING DIMENSIONS BASED ON M2

\begin{tabular}{|c|c|c|c|c|c|c|c|c|c|c|c|c|c|c|}
\hline \multirow{2}{*}{ Factor } & \multicolumn{7}{|c|}{ Survey 1} & \multicolumn{7}{|c|}{ Survey 2} \\
\hline & Min & Max & Mean & SD & Skewness & Kurtosis & $\begin{array}{l}\text { Shapiro- } \\
\text { Wilk Sig. }\end{array}$ & Min & Max & Mean & SD & Skewness & Kurtosis & $\begin{array}{l}\text { Shapiro- } \\
\text { Wilk Sig. }\end{array}$ \\
\hline $\begin{array}{l}\text { Students' preference } \\
\text { towards systems } \\
\text { thinking theories }\end{array}$ & 1.7 & 7.0 & 5.5 & 0.805 & -0.869 & 2.443 & 0.00 & 1.0 & 7.0 & 5.0 & 1.123 & -0.851 & 0.843 & 0.00 \\
\hline $\begin{array}{l}\text { Students interest in } \\
\text { systems thinking } \\
\text { methodologies }\end{array}$ & 1.8 & 7.0 & 5.6 & 0.813 & -0.621 & 1.382 & 0.00 & 2.2 & 7.0 & 5.4 & 0.838 & -0.526 & 0.551 & 0.03 \\
\hline $\begin{array}{l}\text { Students inclination } \\
\text { toward systems } \\
\text { thinking practice }\end{array}$ & 3.0 & 7.0 & 5.5 & 0.759 & -0.272 & -0.203 & 0.01 & 2.4 & 7.0 & 5.3 & 0.833 & -0.508 & 0.385 & 0.04 \\
\hline
\end{tabular}

TABLE IV

CORRELATIONS BETWEEN FACTORS

\begin{tabular}{|c|c|c|c|c|c|c|}
\hline & \multicolumn{3}{|c|}{ Survey 1} & \multicolumn{3}{|c|}{ Survey 2} \\
\hline & Factor1 & Factor2 & Factor3 & Factor 1 & Factor 2 & Factor 3 \\
\hline Students' preference towards systems thinking theories & - & & & - & & \\
\hline Students interest in systems thinking methodologies & $0.778^{* *}$ & - & & $0.446^{* * *}$ & - & \\
\hline Students inclination toward systems thinking practice & $0.746^{* *}$ & $0.645^{* *}$ & - & $0.418^{* *}$ & $0.499^{* *}$ & - \\
\hline
\end{tabular}

TABLE V

MANN-Whitney U TEST RESUlTS FOR ANALYSIS OF QUESTIONS DIFFERENCE

\begin{tabular}{cccccc}
\hline \hline Questions & $\begin{array}{c}\text { Survey 1 } \\
\text { Median } \\
(n=186)\end{array}$ & $\begin{array}{c}\text { Survey 2 } \\
\text { Median } \\
(n=163)\end{array}$ & $U$ & $z$ & $p$ \\
\hline 11 & 6.0 & 5.0 & 14766.00 & -.432 & 0.666 \\
12 & 6.0 & 6.0 & 14004.50 & -1.290 & 0.197 \\
13 & 6.0 & 5.0 & 11327.50 & -4.196 & 0.000 \\
15 & 6.0 & 5.0 & 11468.50 & -4.071 & 0.000 \\
16 & 6.0 & 6.0 & 12564.00 & -2.889 & 0.004 \\
17 & 6.0 & 5.0 & 13152.00 & -2.211 & 0.027 \\
18 & 6.0 & 5.0 & 12585.00 & -2.842 & 0.004 \\
21 & 5.0 & 6.0 & 14873.00 & -.316 & 0.752 \\
22 & 6.0 & 5.0 & 14521.00 & -.705 & 0.481 \\
24 & 5.0 & 5.0 & 14633.00 & -.577 & 0.564 \\
25 & 6.0 & 5.0 & 11797.50 & -3.693 & 0.000 \\
26 & 6.0 & 6.0 & 14917.50 & -.273 & 0.785 \\
27 & 6.0 & 6.0 & 14087.00 & -1.189 & 0.234 \\
28 & 6.0 & 5.0 & 11394.00 & -.116 & 0.000 \\
29 & 6.0 & 6.0 & 14111.00 & -1.164 & 0.244 \\
30 & 6.0 & 6.0 & 14816.50 & -.380 & 0.704 \\
\hline \hline
\end{tabular}

\section{Question 2: Gender Differences}

To examine gender differences in engagement with the ST factors we used the Mann-Whitney $\mathrm{U}$ test again, to compare medians of each group (male and female) at $p<0.005$.

The Mann-Whitney U test applied to the Survey 1 data revealed no significant differences in the preference towards ST theories (factor 1); the interest in ST methodologies (factor 2 ); and the inclination towards ST practice (factor 3) levels between males and females.

The Mann-Whitney $U$ test also revealed no significant differences in the preference towards ST theories (factor 1); the interest in ST methodologies (factor 2); and the inclination towards ST practice (factor 3 ) between males and females in
Survey 2. The result of the Mann-Whitney $\mathrm{U}$ tests are presented in Table VI.

\section{E. Question 3: Age related differences}

To test age related differences in students' engagement to the ST factors, we used the Kruskal-Wallis test, a nonparametric alternative to a one-way between-groups analysis of the variance, to compare the scores of three age groups at $p<0.005$. We divided the sample into three age groups (19$28,29-38$ and >=39). Ranges of five, or ten, years are commonly used in analyzing demographic questions. Ten years was chosen, rather than five years, to compare age levels in this study considering the minimum, maximum and distribution of age in the sample. If five year ranges had been chosen, some groups would have very few participants.

The Kruskal-Wallis test applied to Survey 1 revealed no statistically significant differences in students' engagement to the three ST factors levels across the three age groups (Group 1, $n=108$ : $119-28$ years; Group 2, $n=44: 29-38$ years; Group 3, $n=10:>=39$ years).

The Kruskal-Wallis test applied to Survey 2 revealed no statistically significant differences in the preference towards ST theories (factor 1) and the interest in ST methodologies (factor 2) across the three age groups. However, there is a statistically significant difference in students' inclination towards ST practice (factor 3 ) across the age groups. The older age group $(>=39$ years) recorded a higher median score than the other two age groups. Although the equivalent result in Survey 1 is not statistically significant, the $p$ value is much lower than the $p$ value for the two younger groups in Survey 1.

This suggests that there is an age related factor associated with the ST practice factor although not with the other two. The results of the Kruskal-Wallis tests are presented in Table VII. 
TABLE VI

MANN-WHITNEY U TEST RESULTS FOR ANALYSIS OF GENDER DIFFERENCE

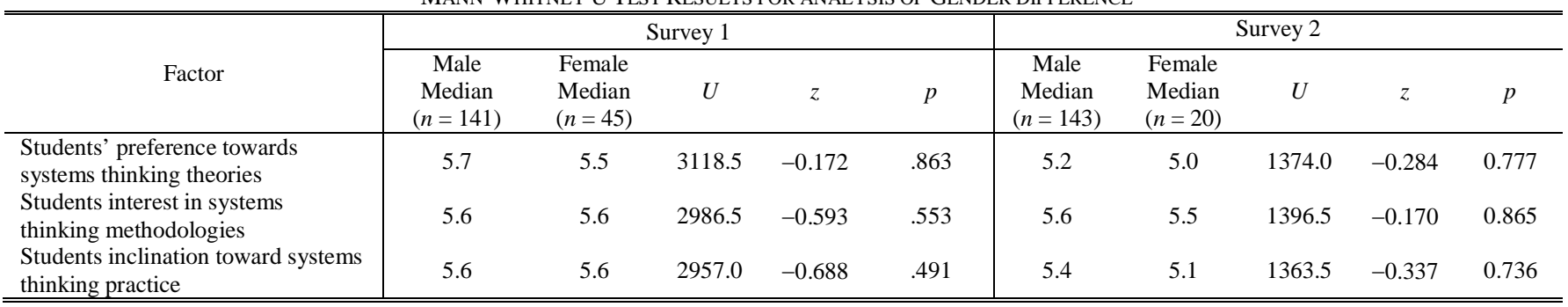

TABLE VII

KRUSKAL-WALLIS TEST RESULTS FOR ANALYSIS OF AGE GROUP RELATED DIFFERENCE

\begin{tabular}{|c|c|c|c|c|c|c|c|c|c|c|c|c|}
\hline \multirow[b]{2}{*}{ Factor } & \multicolumn{6}{|c|}{ Survey 1} & \multicolumn{6}{|c|}{ Survey 2} \\
\hline & $\begin{array}{c}19- \\
28(n=137)\end{array}$ & $\begin{array}{c}29-38 \\
(n=39)\end{array}$ & $\begin{aligned}> & =39 \\
(n & =10)\end{aligned}$ & $\chi^{2}$ & $d f$ & $p$ & $\begin{array}{c}19- \\
28(n=108)\end{array}$ & $\begin{array}{c}29-38 \\
(n=44)\end{array}$ & $\begin{aligned}> & =39 \\
(n & =10)\end{aligned}$ & $\chi^{2}$ & $d f$ & $p$ \\
\hline $\begin{array}{l}\text { Students' preference towards } \\
\text { systems thinking theories }\end{array}$ & 5.7 & 5.8 & 5.8 & 0.214 & 2 & 0.899 & 5.2 & 5.5 & 4.9 & 1.439 & 2 & 0.487 \\
\hline $\begin{array}{l}\text { Students interest in systems thinking } \\
\text { methodologies }\end{array}$ & 5.6 & 5.6 & 5.9 & 0.630 & 2 & 0.730 & 5.4 & 5.6 & 5.9 & 2.094 & 2 & 0.351 \\
\hline $\begin{array}{l}\text { Students inclination toward systems } \\
\text { thinking practice }\end{array}$ & 5.4 & 6.0 & 5.6 & 4.499 & 2 & 0.105 & 5.2 & 5.6 & 5.9 & 6.020 & 2 & 0.049 \\
\hline
\end{tabular}

\section{F. Question 4: Work experience related differences}

To test work experience related differences in students' engagement with the ST factors we used the Kruskal-Wallis test to compare the scores of four work experience groups at $p<0.005$.

The Kruskal-Wallis test applied to Survey 1 revealed no statistically significant differences in the preference towards ST theories (factor 1) and the interest in ST methodologies (factor 2) across the four work experience levels (Group 1, $n=66:<1$ year; Group 2, $n=48: 1-5$ years; Group 3, $n=27$ : 6-10 years; Group 4, $n=22,>10$ years). We divided the sample into four work experience groups $(<1$ year, $1-5$ years, $6-10$ years and $>10$ years). The grouping of work experience was based on the minimum, maximum and distribution of work experience in our sample. Grouping into five year ranges was considered to provide a good representation of work experience distribution because these ranges are frequently used by others for classification of amount of work experience. Each group was represented by a reasonable number of participants.

However, there is a statistically significant difference in students' inclination towards ST practice (factor 3) levels across the work experience groups. The longest work experience group (>10 years) recorded a higher median score than the other groups.

The Kruskal-Wallis test applied to Survey 2 revealed no statistically significant differences in the preference towards ST theories (factor 1) and the interest in ST methodologies (factor 2) across four work experience levels. However, there is a statistically significant difference in students' inclination towards ST practice (factor 3) levels across the work experience groups. The longest work experience group $(>10$ years) recorded a higher median score than the other groups.
These results indicate a work experience factor associated with interest in ST practice. The results of the Kruskal-Wallis Tests are presented in Table VIII.

\section{G. Question 5: Universities/countries related differences}

We used the Kruskal-Wallis test to compare the scores of students from four universities and locations in Survey 1 and three universities and locations groups in Survey 2. This test revealed statistically significant differences toward the three dimensions of ST (Australia, $n=26$; Singapore, $n=50$; US, $n=52$; Indonesia, $n=58$ ) at $p<0.005$. Participants from Australia recorded a lower median score than participants from other countries toward the three dimensions of ST. When applied to Survey 2 this test revealed no statistically significant differences in the preference towards ST theories and interest in ST methodologies across three origin universities. However, there is a statistically significant difference in students' inclination towards ST practice across the location groups. As with Survey 1, participants from Australia recorded a lower median score than other participants toward ST practice. The results of the KruskalWallis Tests are presented in Table IX.

\section{DISCUSSION AND CONCLUSION}

In the absence of quantitative research about affective engagement with ST in SE education, we have applied two self-report surveys which we have previously validated and demonstrated map into the same interpretive model (M2) to measure undergraduate engineering students' engagement with systems thinking and its relationship with gender, age, work experience and country of the origin university

We have analyzed the data for the two studies separately using the M2 model and made conclusions as follow.

Participants in both studies have valued ST in their experience as developing engineers by showing a positive 
attitude when engaging with the three ST factors: the preference towards ST theories; the interest in ST methodologies; and the inclination towards ST practice.
Results in both studies suggest that students who have a positive attitude when engaging with

TABLE VIII

KRUSKAL-WALLIS TEST RESULTS FOR ANALYSIS OF WORK EXPERIENCE GROUP RELATED DIFFERENCE

\begin{tabular}{|c|c|c|c|c|c|c|c|c|c|c|c|c|c|c|}
\hline \multirow[b]{2}{*}{ Factor } & \multicolumn{7}{|c|}{ Survey 1} & \multicolumn{7}{|c|}{ Survey 2} \\
\hline & $\begin{array}{l}<1 \text { year } \\
(n=78)\end{array}$ & $\begin{array}{c}1-5 \text { years } \\
(n=59)\end{array}$ & $\begin{array}{c}6-10 \text { years } \\
(n=27)\end{array}$ & $\begin{array}{c}>10 \text { years } \\
(n=22)\end{array}$ & $\chi^{2}$ & $d f$ & $p$ & $\begin{array}{l}<1 \text { year } \\
(n=66)\end{array}$ & $\begin{array}{l}1-5 \text { years } \\
(n=48)\end{array}$ & $\begin{array}{c}6-10 \text { years } \\
(n=27)\end{array}$ & $\begin{array}{l}>10 \text { years } \\
(n=22)\end{array}$ & $\chi^{2}$ & $d f$ & $p$ \\
\hline $\begin{array}{l}\text { Students' preference towards } \\
\text { systems thinking theories }\end{array}$ & 5.7 & 5.5 & 5.7 & 6.0 & 3.606 & 3 & 0.307 & 5.2 & 5.2 & 5.0 & 5.2 & 0.024 & 3 & 0.999 \\
\hline $\begin{array}{l}\text { Students interest in systems } \\
\text { thinking methodologies }\end{array}$ & 5.8 & 5.2 & 5.4 & 5.8 & 5.520 & 3 & 0.137 & 5.4 & 5.6 & 5.6 & 5.8 & 2.877 & 3 & 0.411 \\
\hline $\begin{array}{l}\text { Students inclination toward } \\
\text { systems thinking practice }\end{array}$ & 5.4 & 5.4 & 6.0 & 6.0 & 9.878 & 3 & 0.020 & 5.2 & 5.4 & 5.4 & 6.0 & 10.364 & 3 & 0.016 \\
\hline
\end{tabular}

TABLE IX

KRUSKAL-WALLIS TEST RESULTS FOR ANALYSIS OF WORK EXPERIENCE GROUP RELATED DIFFERENCE

\begin{tabular}{|c|c|c|c|c|c|c|c|c|c|c|c|c|c|}
\hline \multirow[b]{2}{*}{ Factor } & \multicolumn{7}{|c|}{ Survey 1} & \multicolumn{6}{|c|}{ Survey 2} \\
\hline & $\begin{array}{c}\text { Australia } \\
(n=26)\end{array}$ & $\begin{array}{c}\text { Singapore } \\
(n=50)\end{array}$ & $\begin{array}{c}\mathrm{US} \\
(n=52)\end{array}$ & $\begin{array}{c}\text { Indonesia } \\
(n=58)\end{array}$ & $\chi^{2}$ & $d f$ & $p$ & $\begin{array}{c}\text { Australia } \\
(n=91)\end{array}$ & $\begin{array}{c}\text { Singapore } \\
(n=59)\end{array}$ & $\begin{array}{c}\mathrm{US} \\
(n=13)\end{array}$ & $\chi^{2}$ & $d f$ & $p$ \\
\hline $\begin{array}{l}\text { Students' preference towards } \\
\text { systems thinking theories }\end{array}$ & 5.0 & 5.7 & 5.8 & 5.7 & 12.537 & 3 & .006 & 5.2 & 4.7 & 6.0 & 5.392 & 2 & .067 \\
\hline $\begin{array}{l}\text { Students interest in systems } \\
\text { thinking methodologies }\end{array}$ & 4.7 & 5.6 & 5.7 & 5.8 & 21.194 & 3 & .000 & 5.6 & 5.6 & 5.6 & 1.528 & 2 & .466 \\
\hline $\begin{array}{l}\text { Students inclination toward } \\
\text { systems thinking practice }\end{array}$ & 4.8 & 5.8 & 5.7 & 5.4 & 19.258 & 3 & .000 & 5.2 & 5.6 & 5.8 & 9.348 & 2 & .009 \\
\hline
\end{tabular}

one dimension of ST tend to rate themselves as valuing ST in other dimensions.

No significant gender differences in engagement with the three ST factors were found in either survey. This implies that there is no difference in educating male and female students in systems thinking in undergraduate SE education and therefore no special teaching method is needed for each gender.

However, there are variations in students 'engagement with ST in relation to their age and work experience. Whilst we found age and work experience related association, at the high end of both variables and interest in ST practice, the age and experience factors did not show the same increase with respect to ST theory and methodologies.

This study confirmed that engagement with practical systems thinking was significantly associated with age and work experience. It shows that the older and the greater the experience of students, the higher their engagement with practical systems thinking. This result suggests that ST practices are something that life and work experience promotes, possibly as a result of experiencing limitations of not using ST.

Previous studies suggested that experience is an important promoter of ST development in individuals [7] and groups [19]. However, there was no categorization of ST in the previous studies. Our work shows that the only ST factor which affects engagement is the practice related factor.

This result implies that an experiential learning environment is important for developing students' engagement with ST practice. For young students with limited work experience, as is true for the most students in undergraduate SE education, the more experiential learning experiences during their study will boost their cognitive development in ST. This implication is relevant with Turnquist et al. [64], Gonçalves [65] and Caldwell [66] who suggested the involvement of students in projects is vital in SE education because it allows students to get experiential learning by engaging in group activities and represents the professional work [64-66]. Therefore, moving from traditional lecture-based methods to methods that focus on student experience to accelerate development of systems engineers for handling the dynamic project environments of the real world is important to be considered by SE educators [65].

Project-based learning, a teaching and learning model that emphasizes student-centred instruction by assigning a project, to be addressed using self-direction, collaboration and multidisciplinary orientation, appears to enable students' experiential learning $[67,68]$. Further study is possibly needed to examine the relationship of project-based learning with the development of students' affective engagement with ST. This further work could usefully compare project-based learning with a traditional lecture-based method for the purpose of developing students' affective engagement with ST.

The students' engagement with the theoretical and methodological aspects of ST were not affected by age and work experience. This suggests that people are inherently interested or not interested in ST theories and methodologies. SE education needs to ensure that both of students' engagement with ST theories and methodologies are developed in SE education, as these will not grow as age and work experience increase. Thus the students, inherently interested or not interested, can become characterized by their elevated valuation of the ST subject that they have learned during their SE program.

To respond to these findings and concerns universities need to provide students with ST courses. However, such courses are not currently offered. Our review of the curriculum of 33 institutions in the US and Australia listed in the INCOSE website and which provide undergraduate domain-centric or systems-centric SE programs shows that most of these institutions do not offer their students a specific ST course. Consequently, most tertiary institutions do not provide their 
students with a specific ST course that offers knowledge of and affective engagement with ST theories and methodologies.

To maximize students' learning in the affective domain in relation to ST theories and methodologies, SE educators can integrate the affective domain into teaching methods. For example, to fulfil student's cognitive and affective learning needs, SE educators can simplify the explanation of a complex concept before delivering a lecture by using brainstorming or concept mapping [36]. Positive reinforcement such as rewards during the class can lead students towards continued efforts and goal accomplishment. SE educators can also develop students' engagement with the cognitive content through multimedia (pictures, 3-dimensional models, sound and video), fun class activities and applying different strategies for different texts such as 'coloring' the text by relating the text with students' affective experiences [29]. Persuasive communicative skills can be utilized as a strategy to develop students' emotional attachment to learning while performing cognitive reconstruction $[33,36]$.

Finally, there is a statistically significant difference in students' inclination towards ST practice across the countries of the origin universities in both surveys, with a lower median score recorded for students from the Australian university than other participants. However, this result may actually be influenced by university characteristics other than country, since only one university from each country was included in each survey. This result needs further investigation to determine the cause, with possible origins of the effect including ethnic culture, education offered by the university or the people the university attracts to become students.

The present work has measured the engagement with ST of undergraduate students in a single snap-shot form. The lessons learned during the design of the study, implementation and configuration of all necessary elements for data collection and data analysis of these surveys contributes to methodology in research in systems engineering education. The lessons learned during this study also suggested further studies in measuring and monitoring students' affective engagement with ST during a specific interval by collecting a time series of data to study changes or continuity in the sample's characteristics [54]. In particular it is necessary to investigate whether education in SE and ST makes a difference to the students score in this test and whether there may be some student cohort or subgrouping where SE education is more or less effective in generating improvement in test scores. In addition, the findings from this work have implications for practice in SE education. By investigating students' ST in undergraduate SE education level, it is expected that this study can fill the gap in quantitative research about the affective engagement with ST in SE education and the correlations of ST with other student attributes which have not been explored.

\section{ACKNOWLEDGEMENT}

The authors thank Moti Frank for providing additional useful information about his previous work. The authors also thank the academic staff who assisted this research through inviting students in their classes to participate in the survey. These academic staff work in four universities in four countries but cannot be named to maintain confidentiality, as required under the ethics protocol.

\section{REFERENCES}

[1] D. Cabrera, "Systems thinking," Doctor of Philosophy Dissertation, Faculty of the Graduate School of Cornell University, Cornell University, 2006.

[2] F. Camelia, T. L. J. Ferris, and D. H. Cropley, "Development and initial validation of an instrument to measure students' learning about systems thinking: The affective domain " in Systems Journal, IEEE, ed, 2015.

[3] D. Cabrera, L. Cabrera, and E. Powers, "A Unifying Theory of Systems Thinking with Psychosocial Applications," Systems Research and Behavioral Science, vol. 32, pp. 534-545, 2015.

[4] K. Brandstädter, U. Harms, and J. Großschedl, "Assessing system thinking through different concept-mapping practices," International Journal of Science Education, vol. 34, pp. 2147-2170, 2012.

[5] G. Schiuma, D. Carlucci, and F. Sole, "Applying a systems thinking framework to assess knowledge assets dynamics for business performance improvement," Expert Systems with Applications, vol. 39, pp. 8044-8050, Jul 2012.

[6] J. Kasser, M. Frank, and Y. Y. Zhao, "Assessing the competencies of systems engineers," in 7th Bi-annual European Systems Engineering Conference (EUSEC), Stockholm, Sweden, 2010, p. 2010.

[7] H. L. Davidz, "Enabling systems thinking to accelerate the development of senior systems engineers," Doctor of Philosophy, Engineering Systems Division, Massachusetts Institute of Technology, 2006.

[8] O. J. H. Bosch, C. A. King, J. L. Herbohn, I. W. Russell, and C. S. Smith, "Getting the big picture in natural resource management-systems thinking as "method' for scientists, policy makers and other stakeholders," Systems Research and Behavioral Science, vol. 24, pp. 217-232, 2007.

[9] G. Midgley, "Response to paper "Systems thinking" by D. Cabrera et al.: The unification of systems thinking: Is there gold at the end of the rainbow?," Evaluation and Program Planning, vol. 31, pp. 317-321, $8 / 2008$.

[10]H. L. Davidz, D. J. Nightingale, and D. H. Rhodes, "Accelerating the development of senior systems engineers," in The 15th Annual International Symposium INCOSE 2005, pp. 10-15.

[11]M. Frank, "What is "engineering systems thinking"?," Kybernetes, vol. 31, pp. 1350-1360, 2002.

[12]M. Frank, "Engineering systems thinking and systems thinking," Systems Engineering, vol. Vol. 3, pp. 163-167, 2000.

[13]M. Frank, "Characteristics of engineering systems thinking-A 3-D approach for curriculum content," IEEE Transaction on Systems, Man, and Cybernetics-Part C: Applications and Reviews, vol. 32, pp. 203214, Aug 2002.

[14]M. Frank, "Knowledge, abilities, cognitive characteristics and behavioral competencies of engineers with high capacity for engineering systems thinking (CEST)," System Engineering, vol. Vol. 9, pp. 91-103, 2005.

[15]M. Frank, O. Zwikael, and M. Boasson, "Jobs requiring a capacity for engineering systems thinking (CEST): Selection using an interest inventory," Project Management vol. 38, pp. 36-44, 2007.

[16]M. Frank and S. Kordova, "Developing the capacity for engineering systems thinking (CEST) of senior engineering management students: Learning in a project-based learning (PBL) environment," in 7th Annual Conference on Systems Engineering Research (CSER 2009), Loughborough, Leicestershire, UK, 2009.

[17]M. Frank, "Assessing the interest for systems engineering positions and other engineering positions' required capacity for engineering systems thinking (CEST)," Systems Engineering, vol. 13, pp. 161-174, 2010.

[18]M. Frank, "Towards a 4-d systems engineering cognitive competency model," in INCOSE International Symposium Las Vegas, Nevada, USA, 2014.

[19]C. M. T. Lamb, "Collaborative Systems Thinking: An exploration of the mechanisms enabling team systems thinking," Doctor of Philosophy, Department of Aeronautics and Astronautics, Massachusetts Institute of Technology, 2009.

[20]N. C. Nguyen, D. Graham, H. Ross, K. Maani, and O. Bosch, "Educating systems thinking for sustainability: experience with a developing country," Systems Research and Behavioral Science, vol. 29, pp. 14-29, 2012.

[21]S. Witjes, P. M. Specht, and C. M. Rodriguez, "The measurement of the development of systems and general thinking in agricultural areas of Colombia; preliminary results," in 50th Annual Meeting of the ISSS, 2006. 
[22]C. Foster, M. Crowder, K. Nelson, and T. Ganesh, "Work in progress Developing engineering systems thinking through the modeling of a complex bioengineering system," in Frontiers in Education Conference (FIE), pp. 1-2, 2012.

[23]J. K. Doyle, M. J. Radzicki, and W. S. Trees, "Measuring change in mental models of complex dynamic systems," in Complex Decision Making, ed: Springer, 2008, pp. 269-294.

[24]L. B. Sweeney and J. D. Sterman, "Bathtub dynamics: initial results of a systems thinking inventory," System Dynamics Review, vol. 16, pp. 249 286, Win 2000

[25]K. Y. H. Connell, S. M. Remington, and C. M. Armstrong, "Assessing systems thinking skills in two undergraduate sustainability courses: a comparison of teaching strategies," Journal of Sustainability Education, vol. 3, 2012

[26]W. Hung, "Enhancing systems-thinking skills with modelling," British Journal of Educational Technology, vol. 39, pp. 1099-1120, 2008.

[27]B. S. Bloom, M. D. Engelhart, E. J. Furst, W. H. Hill, and D. R. Krathwohl, Taxonomy of Educational Objectives the Classification of Educational Goals Handbook I: Cognitive Domain. London: Longman Group Ltd., 1956.

[28]D. R. Lynch, J. S. Russell, J. C. Evans, and K. G. Sutterer, "Beyond the cognitive: The affective domain, values, and the achievement of the vision," Journal of Professional Issues in Engineering Education and Practice, vol. 135, pp. 47-56, 2009

[29]W. Zhang and J. Lu, "The practice of affective teaching: A view from brain science," International Journal of Psychological Studies, vol. 1, pp. 35-41, 2009.

[30]K. Shephard, "Higher education for sustainability: seeking affective learning outcomes," International Journal of Sustainability in Higher Education, vol. 9, pp. 87-98, 2008.

[31]J. Hanus, S. Hamilton, and J. S. Russel, "The cognitive and affective domain in assessing the life-learning objectives," American Society for Engineeering Education, 2008.

[32]L. F. Denton and D. McKinney, "Affective factors and student achievement: A quantitative and qualitative study," in IEEE Frontiers in Education Conference, Savannah, GA, USA, 2004

[33]T. A. Lashari, M. Alias, Z. A. Akasah, and M. J. Kesot, "An affective cognitive teaching and learning framework in engineering education," ASEAN Journal of Engineering Education, vol. 1, pp. 11-24, 2012.

[34]Y. S. Rivera, "Promoting motivation through mode of instruction: the relationship between use of affective teaching tachniques and motivation to learn science," Doctor of Education, Lehigh University, 2010.

[35] S. P. Schmidt, "An evaluation of teaching method in theological education " in Voice of The Church in Asia, ed Singapore: Asia Theological Association, 1975, pp. 36-49.

[36]M. Alias, T. A. Lashari, Z. A. Akasah, and M. J. Kesot, "Translating theory into practice: integrating the affective and cognitive learning dimensions for effective instruction in engineering education," European Journal of Engineering Education, vol. 39, pp. 212-232, 2013.

[37]S. M. G. Gondim and C. Mutti, "Affections in learning situations: A study of an entrepreneurship skills development course," Journal of Workplace Learning, vol. 23, pp. 195-208, 2009.

[38]A. Boyle, S. Maguire, A. Martin, C. Milsom, R. Nash, S. Rawlinson, et al., "Fieldwork is good: the student perception and the affective domain," Journal of Geography in Higher Education, vol. 31, pp. 299-317, May 2007.

[39]D. Wilson and R. C. Campbell, "Workshop-filling in the gaps: The use of affective outcomes in engineering \& CSET education research," in ASEE/IEEE Frontiers in Education Conference, San Antonio, TX, USA, 2009.

[40]T. L. J. Ferris, "Bloom's affective domain in systems engineering education," presented at the 5th Asia-Pasific Conference on System Engineering (APCOSE), Seoul, Korea, 2011.

[41] P.-K. Lin, P.-C. Lin, and S.-Y. Li, "Workplace competencies in demand: Perception gaps between service industries and manufacturing industries," in 9th International Conference on Service Systems and Service Management (ICSSSM), Shanghai, China, 2012, pp. 639-642.

[42]M. Barnes, M. Bailey, R. R. Green, and D. A. Foster, "Teaching embedded microprocessor systems by enquiry-based group learning," International Journal of Electrical Engineering Education, vol. 43, pp. 114, Jan 2006

[43]B. N. Atsumbe and T. M. Saba, "A study on affective work skills needs of engineering and technology education students of universities in north central states of Nigeria," Bayero Journal of Pure and Applied Sciences, vol. 1, pp. 95-98, 2008
[44]T. L. Ferris, A. F. Squires, and F. Camelia, "Integrating Affective Engagement into Systems Engineering Education Paper," in 2015 ASEE Annual Conference and Exposition, Seattle, Washington, 2015, pp. 26.985.1 - 26.985.17.

[45]D. R. Haws, "Ethics instruction in engineering education: A (mini) metaanalysis," Journal of Engineering Education, vol. 90, pp. 223-229, 2001.

[46]R. J. MacFadden and D. Schoech, "Neuroscience, the Unconscious and Professional Decision Making: Implications for ICT," Journal of Technology in Human Services, vol. 28, pp. 282-294, 2010.

[47]G. Coricelli, R. J. Dolan, and A. Sirigu, "Brain, emotion and decision making: the paradigmatic example of regret," Trends in Cognitive Sciences, vol. 11, pp. 258-265, 6/2007.

[48]A. Bechara, "The role of emotion in decision-making: Evidence from neurological patients with orbitofrontal damage," Brain and Cognition, vol. 55, pp. 30-40, 6/2004.

[49]S. R. Quartz, "Reason, emotion and decision-making: risk and reward computation with feeling," Trends in Cognitive Sciences, vol. 13, pp. 209$215,5 / 2009$.

[50]F. Camelia and T. L. J. Ferris, "Methods to evaluate the effectiveness of a systems thinking course in the context of systems engineering education," in Systems Engineering Test and Evaluation Conference Canberra, 2015.

[51]F. Camelia and T. L. J. Ferris, "Evaluation of a rubric for measuring systems thinking development of undergraduate students," unpublished.

[52]F. Camelia and T. L. J. Ferris, "Validation studies of a questionnaire development to measure students' engagement with systems thinking," unpublished.

[53]W. Fabrycky, "Systems Engineering: It's emerging academic and professional attributes," in American Society for Engineering Education (ASEE) Annual Conference and Exposition Conference, Louisville, Kentucky, 2010.

[54]M. D. Gall, J. P. Gall, and W. R. Borg, Educational Research: An Introduction, 8th ed. Boston, MA: Pearson Education, Inc., 2007.

[55]D. M. Mertens, Research Methods in Education and Psychology: Integrating Diversity with Quantitave and Qualitative Approaches. Thousand Oak: Sage Publications, Inc., 1998.

[56]M. Frank, "Assesing interest for systems engineering positions' required capacity for engineering systems thinking (CEST)," Systems Engineering, vol. 13 , pp. 161-174, 2010.

[57]B. Johnson and L. Christensen, Educational Research: Quantitative, Qualitative, and Mixed Approaches, 4th ed.: SAGE Publications, Inc., 2012.

[58]S. J. Kline, Conceptual Foundations for Multidisciplinary Thinking. California: Stanford University Press, 1995.

[59]P. B. Checkland and S. Holwell, Information, Systems and Information Systems. Chichester: Wiley, 1998.

[60]D. M. Windish and M. Diener-West, "A Clinician-Educator's Roadmap to Choosing and Interpreting Statistical Tests," Journal of General Internal Medicine, vol. 21, pp. 656-660, 2006.

[61]H. M. Park, "Comparing Group Means: T-test and One-way ANOVA Using Stata, SAS, R, and SPSS," I. U. The University Information Technology Services (UITS) Center for Statistical and Mathematichal Computing, Ed., ed, 2009.

[62]J. Pallant, SPSS Survival Manual: A Step-by-Step Guide to Data Analysing using SPSS. Sydney: Allen \& Unwin, 2007.

[63]A. Field, Discovering statistic using SPSS, 3rd ed. Los Angeles, London, New Delhi, Singapore, Washington DC: SAGE, 2009.

[64]M. A. Turnquist, R. D'Andrea, A. R. George, P. Jackson, L. K. Nozick, D. Rhodes, et al., "Designing a systems engineering educational program using academic/industry collaboration," in The 10th Annual International Symposium INCOSE, Minneapolis, Minnesota, 2000.

[65]D. Gonçalves, "Developing systems engineers," in Portland International Conference on Management of Engineering \& Technology (PICMET), pp. 1963-1972, 2008.

[66]B. S. Caldwell, "Perspective of system engineering and impacts on SE education," in Industrial Engineering Research Conference, pp. 217-222, 2009

[67] A. M. Al-Bahi, R. M. S. Abdulaal, A. Y. Soliman, and F. I. Iskanderani, "Introductory project-based design course to meet socioeconomic challenges," presented at the American Society for Engineering Education, 2011.

[68]J. E. Mills and D. F. Treagust, "Engineering education - Is problem-based or project-based learning the answer?," Australasian Journal of Engineering Education, 2003. 


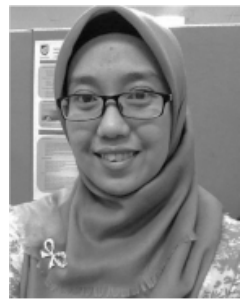

Fanny Camelia received the degrees B.Eng, in industrial engineering, Andalas University, Indonesia, in 2003 and M.PrjMgmt, in applied project management, University of Adelaide, Adelaide, South Australia in 2011. She is currently working toward the Ph.D. degree in systems engineering at University of South Australia, Mawson Lakes, Australia.

From 2003 to 2005, she was a Research Assistant in a collaborative project between Andalas University and Padang Cement Indonesia (now Cement of Indonesia). From 2005 to 2010 , she was a Lecturer with the Ekasakti University, Padang, Indonesia. Her research interests include systems thinking, systems engineering, engineering education, project management, production, logistics and inventory systems.

She was a recipient of Australian Award Scholarship during her master's degree and holds an Indonesia Directorate General of Higher Education (DGHE) Scholarship during her $\mathrm{PhD}$ degree.

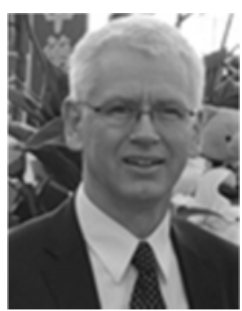

Timothy L.J. Ferris (M'91-SM'02) received the degrees B.E.Hons, University of Adelaide, Adelaide, South Australia in 1982, B.Th., Flinders University, Adelaide, SA in 1988, B.Litt.Hons., Deakin University, Geelong, Victoria in 1991, GradCertEd, Queensland University of Technology, Brisbane, Queensland in 2002, and PhD, University of South Australia, Adelaide, SA in 1997. All these universities are in Australia. His $\mathrm{PhD}$ was in the area of the theory of measurement.

He worked as an Engineer for the Electricity Trust of South Australia and Morrison Court Pty Ltd, and as a Church Worker in the Presbyterian Church of Australia before commencing as a faculty member in engineering in University of South Australia, at Mawson Lakes, South Australia, in 1991. He is currently working at Cranfield University, at Shrivenham, UK. He has published about 130 papers in journals and conferences and various other contributions to the scholarly literature. His current research interests relate to foundational issues in systems engineering, cross cultural issues in systems engineering, engineering education and research methods.

Dr Ferris is a member of INCOSE. He was Secretary of the IEEE South Australia Section (2004-2005), Publication Chair for the SoSE 2014 conference, and is an Associate Editor of IEEE Systems Journal. 